\title{
ENANISMO: REPRESENTACIONES ARTÍSTICAS EN AMÉRICA PREHISPÁNICA Y OTRAS SOCIEDADES
}

\author{
Hugo Sotomayor Tribín M D*
}

\section{Introducción:}

La representación de patologías en el arte en las sociedades prehispánicas de al gunas regiones que hoy corresponden a M éxico y Guatemala núcleos de la llamada Mesoamérica arqueológica, Costa Rica, Colombia y Ecuador constituyentes en términos arqueológicos a la A mérica intermedia y Perú y Bolivia definitorios de los A ndes centrales, es una fuente muy importante para conocer la pal eopatología de la A mérica antigua o precolombina, aún de las sociedades que no dejaron o que se desconocen estos testimonios artísticos.

L as sociedades que dejaron piezas de arte de gran significación para la paleopatología fueron aquellas que superaron el modo de producción de cazadores recolectores, los hábitos de la vida nómada y que alcanzaron ciertos niveles de especialización en la producción de bienes agrícolas. Ellas constituyen en general los desarrollos regionales, preclásicos, clásicos y posclásicos, que se extienden en el tiempo desde las más antiguas alrededor del 1500 a.C como la mexicana O Imeca, hasta las más recientes en el siglo XV como la colombo ecuatoriana $N$ ariñoCarchi.

Este arte de importancia para los estudios de la paleopatología para ser valorado en su completo significado médico patológico, debe ser contrastado, complementado y contextualizado con los datos que cada día se obtienen del estudio con metodologías modernas, como las imágenes diagnósticas y las técnicas moleculares de los diferentes tipos de restos humanos (huesos, dientes, momias, fitolitos, coprolitos, etc.), así como los derivados de las interpretaciones que puedan hacerse de las tempranas informaciones históricas que sobre las sociedades indígenas dejaron los cronistas españoles y de otras naciones, y de las etnohistorias que los científicos sociales han podido reconstruir de los herederos y descendientes de los responsables de aquel arte.

U na fuente importante, no para el análisis del tipo de patología representada según la taxonomía médica científica moderna, sino para el estudio del significado, el simbolismo o la metáfora de la deformidad, el defecto, la mutilación o la enfermedad, es con seguridad escuchar y estudiar lo que sobre esas representaciones dicen, a partir de un pensamiento analógico, los chamanes de las supérstites culturas o sociedades indígenas de A mérica. ${ }^{1}$

El arte de las representaciones patológicas no sólo es útil para la paleopatología en sentido estricto, sino que como construcción simbólica está en capacidad de ofrecernos, si lo sabemos ver, una gran ventana para conocer mejor los constructos sociales sobre el cuerpo, la salud-enfermedad y la arqueomedicina de los pueblos antiguos.

Las representaciones de las patologías en el arte no sólo son una fuente, concebida por muchos como de menor valor o blanda en comparación con la de mayor valor o dura que representan los estudios sobre los restos humanos, para la cada día más científica paleopatología, sino también es una fuente de enorme importancia para la antropología médica. 
El arte es metonímico, metafórico, polisémico y en no pocas veces anticipa y esclarece los caminos del saber, en apariencia unívoco y monosémico de las ciencias, en especial de las que se llaman sociales 0 humanas de las que en mucho se nutre la medicina y la patología.

Estas precisiones sobre el arte y las representaciones de las patologías en el se ven bien en los apartes que sobre algunas personas diferentes en las sociedades aztecas e incas escribieron H ernán Cortes, B ernal Díaz del Castillo y Felipe Guaman Poma de A yala.

Hernán Cortes relata en sus Cartas de la Conquista deMéxico, que " [M uteczuma]... Tenía en esta casa un cuarto en que tenía hombres y mujeres y niños blancos de su nacimiento en el rostro y cuerpo y cabellos y cejas y pestañas" ... "Tenía una casa donde tenía muchos hombres y mujeres monstruos, en que había enanos, corcovados, y otros con otras diformidades, y cada una manera de monstruos en su cuarto por sí; e también había para éstos personas dedicadas para tener cargo dellos". 2

\section{B ernal Díaz del Castillo cuenta en su Historia verda} dera dela conquista dela Nueva España que en las residencias de "[ M ontezuma]... estaban unos indios corcovados, muy feos, porque eran chicos de cuerpo y quebrados por medio de los cuerpos, que entre ellos eran chocarreros; y otros indios que debían ser truhanes, que le decían gracias, e otros que le cantaban y bailaban, porque el M ontezuma era muy aficionado a placeres y cantares, e a aquéllos mandaba dar los relieves y jarros del cacao". ${ }^{3}$

Felipe Guaman Poma de Ayala escribió, en su obra Nueva crónica y buen gobierno sobre la situación de las personas con defectos físicos, en el Perú: "En esta calle del quarto de los enfermos y liciados, cojos y mancos y tullidos, upa, mudo; nausa, ciego; _uncoc, enfermo; uinay uncoc, tullido; maquin paquisca manco; hanco, coxo. E stos servían de pasatiempo, hablar y cjocarrear, como son enanos, tinre, uayaca; cumo, corcobado; chicta cinca (naríz partida). Cada uno de los que podían trabajar y ayudar, los que tenían ojos servían de mirar, los que tenían pies andaban, los que tenían manos texían y servían de despenseros y quipo camayos, mayordomos. Éstos cada uno les casaban con su igual para multiplicar y servían en todo lo que pudían ... Le casaban al ciego con otra ciega, al cojo con otra coja, al mudo con otra muda, el enano con enana, al corcobado con corcobada, el naríz hendido con otra de naríz hendida, para el multiplico del mundo... . Y éstos tenían sus sementeras, casas, er edades y ayuda de su servicio y ancí no avía menester hospital ni limosna con esta horden santa y pulicía deste rreyno..." .4

Las anteriores observaciones del conquistador de M éxico, el sacerdote cronista y el cronista de ascendencia incaica sobre lo que ellos vieron en los imperios azteca e inca, muestran una realidad que bien pudo ser diferente o parecida a la de las sociedades indígenas americanas, que no llegaron al nivel político administrativo de Estado y se quedaron en el nivel de cacicazgos.

M últiples testimonios recogidos a lo largo de todo el continente americano señal an la muy frecuente práctica del infanticidio sobre niños nacidos con evidentes defectos físicos congénitos como son los que generan reducción corporal (microtia, mano hendida, Iabio leporino) y duplicación de estructuras (polidactilias, siameses, etc.). El infanticidio 0 abandono de uno 0 los dos gemelos fue y es todavía una práctica frecuente entre varias comunidades indígenas en al gunas partes de A mérica, como es el caso de Colombia, muy asociada con el concepto de duplicación de estructuras y seres.

Como la mayor parte de los casos de enanismo que sobreviven después del parto, no se pueden diferenciar con facilidad de los recién nacidos normales y como no tenían una reducción o duplicación de al guna parte del cuerpo, con seguridad lograron llegar a tener varios meses de edad y así recibir un nombre tribal cuando fueron caracterizados como tales. A partir de ese momento se consideraban como seres dotados de características y poderes especiales. La anterior consideración explicaría el por qué de la frecuente representación de enanos en el arte prehispánico americano. 


\section{Material y métodos}

Para la elaboración de este estudio comparativo de obras de arte con representaciones de enanismo en $\mathrm{M} \mathrm{e}$ soamérica, A mérica intermedia y los A ndes centrales con las de las culturas del antiguo E gipto, grecorromanas y las europeas a partir del siglo XV, se tomó como punto de partida la colección que el autor de estas líneas guarda y que está constituida por cerámicas de las culturas Tumaco-L a Tolita, J ama-C oaque, N ariñoCarchi, M alagana y Sinú y $\mathrm{M}$ omil, que ha presentado en diferentes publicaciones ${ }^{5-9}$ y por fotografías de escul turas en piedra y cerámicas de culturas mexicanas, guatemaltecas, costarricenses, ecuatorianas, peruanas y bolivianas, obtenidas de diferentes libros. Entre ellos los titulados Arqueomedicina de Colombia prehispánica y Aproximaciones a la paleopatología en América Latina que el autor tuvo oportunidad de producir, el primero en dos ediciones, 1992 y 1999 y el segundo en 2007 con el auspicio de la A cademia Nacional de M edicina de Colombia, la A sociación L atinoamericana de A cademias Nacionales de M edicina (A LA NA M) y el Convenio A ndrés B ello. Para la comparación con la cultura del antiguo Egipto y de las antiguas Grecia y Roma se tomaron dos ejemplos muy conocidos del primero y seis de la cultura grecorromana. Para hacerlo con la cultura europea del siglo XV en adelante se tomaron doce ejemplos de las grandes obras pictóricas.

Por razones de diagnóstico moderno se tomó como caso de enanismo en el arte las personas representadas con rostro de adul to que es más pequeño de lo habitual, dentro del conjunto de la producción artística de la cultura que creó la obra de arte, y que presente o no una al teración en las proporciones corporales según el estilo artístico de la cultura que creó esa obra de arte.

Con el propósito de hacer el estudio de los enanismos precolombinos se escogieron treinta y un ejemplos de esta patología de la producción artística prehispánica y el cuadro clínico se dividió, con base en las posibilidades que ofrecen las piezas de arte analizadas aquí, en inespecífico y específico. En el primer caso se tomaron veintidós ejemplos: ocho figurinas líticas de las que tres son olmeca, dos maya y tres Tiwanaku, cinco cerámicas mayas, una Colima de M éxico, otra de posible origen de la cultura M alagana, una cerámica Tumaco-L a Tolita y seis pinturas mayas. Del grupo de enanismos con diagnóstico específico se seleccionaron nueve ejemplos: seis cerámicas T umaco-L a Tolita, una M alagana, una cerámica A zteca y otra Chimú.

El primer ejemplo de la cultura del antiguo Egipto pertenece a la VI Dinastía del Imperio A ntiguo (2320 -2250 a.C.) y el segundo a la época grecorromana. LoS seis ejemplos griegos son de cerámicas de pinturas rojas de los siglos IV a II a.C.; el romano, al parecer recuperado en las excavaciones de las dos ciudades sepultadas por la erupción del volcán V esubio, Pompeya y Herculano. Se muestra al dios hindú V isnú convertido en un enano. Los ejemplos de E uropa son doce bellas pinturas que van desde el siglo XV al XV II. Un total de veintiún ejemplos no prehispánicos. ${ }^{10}$ Contrasta con esta abundancia de representaciones del enanismo en el arte, los pocos esquel etos de acondroplásicos, que el autor sepa, se han encontrado en las excavaciones arqueológicas. ${ }^{11-13}$

\section{Enanismo prehispánico inespecífico}

Si bien para efectos operativos aquí se entiende por enanismo inespecífico los casos en que la elaboración de la representación artística solo permite apreciar el aspecto general de la desproporción corporal y baja talla, es necesario recordar que el enanismo más frecuente es el acondroplásico ya que tiene una frecuencia de aparición de un caso por cada quince mil 0 veinte mil nacidos vivos.

En la ciencia moderna las causas pueden ser de origen hormonal, nutricional, por cuadros sindromáticos de muy baja talla con displasias no óseas, de talla baja moderada acompañada de anomalías faciales o genitales, trastornos de depósito, baja talla por defectos de las extremidades, por osteocondrodisplasias o por osteocondrodisplasias con osteopetrosis, como manifestaciones principales. ${ }^{14}$

Todos los casos de enanismo inespecífico y específico presentados en las siguientes representaciones artísticas parecen corresponder a osteocondrodisplasias y 
baja talla por defectos en las extremidades, y a un caso de trastorno de depósito. No hay ejemplos de causas hormonales y/o nutricionales.

En 16 pequeñas figurinas de personajes masculinos, ocho de piedra que corresponden a tres OImeca (Figu ras 1, 2y3), dos M ayas de G uatemala (Figuras4y 5) y tres Tiwanaku (Figuras 6, 7y 8), cinco cerámicas $M$ aya (Figuras9, 10, 11,12y 13), una Colima (Figura 14), una posible de la cultura M alagana (Figura 15) y otra Tumaco-La Tolita (Figura 16), se aprecia con claridad la desproporción corporal y el acortamiento de talla en doce de los ejemplos y la baja talla asociada con giba en los tres de la cultura Tiwanaku y en el de la Colima .

Una pieza lítica OImeca (Figura3) que no aparenta tener enanismo pero si una desproporción corporal, le falta el miembro inferior derecho y muestra un aumento impor- tante del grosor del pie y la pierna izquierdos, que hacen recordar un cuadro de linfedema congénito 0 adquirido y una expresión de sufrimiento representada en el gesto de tener las manos en el pecho y un rostro borroso.

Dos esculturas líticas Olmeca (Figuras 1 y 2) y dos cerámicas $\mathrm{M}$ aya, una de la isla mexicana de J aina (Figura 13) y otra de la guatemalteca Tikal (Figura 9), revelan personajes cortos de estatura a expensas en especial de los miembros inferiores. Las esculturas líticas $M$ aya de Guatemala solo revelan la pequeña talla (Figuras 4 y 5).L a primera y segunda figurinas líticas bolivianas de la cultura Tiwanaku, muestran dos pequeños personajes gibados. (Figuras6y 7 ).

U na tercera figurina lítica boliviana de la cultura Tiwanaku, muestra a un personaje enano con una gran giba y un enorme pene erecto (Figura 8). El enanismo con acortamiento de las cuatro extremidades se aprecia en
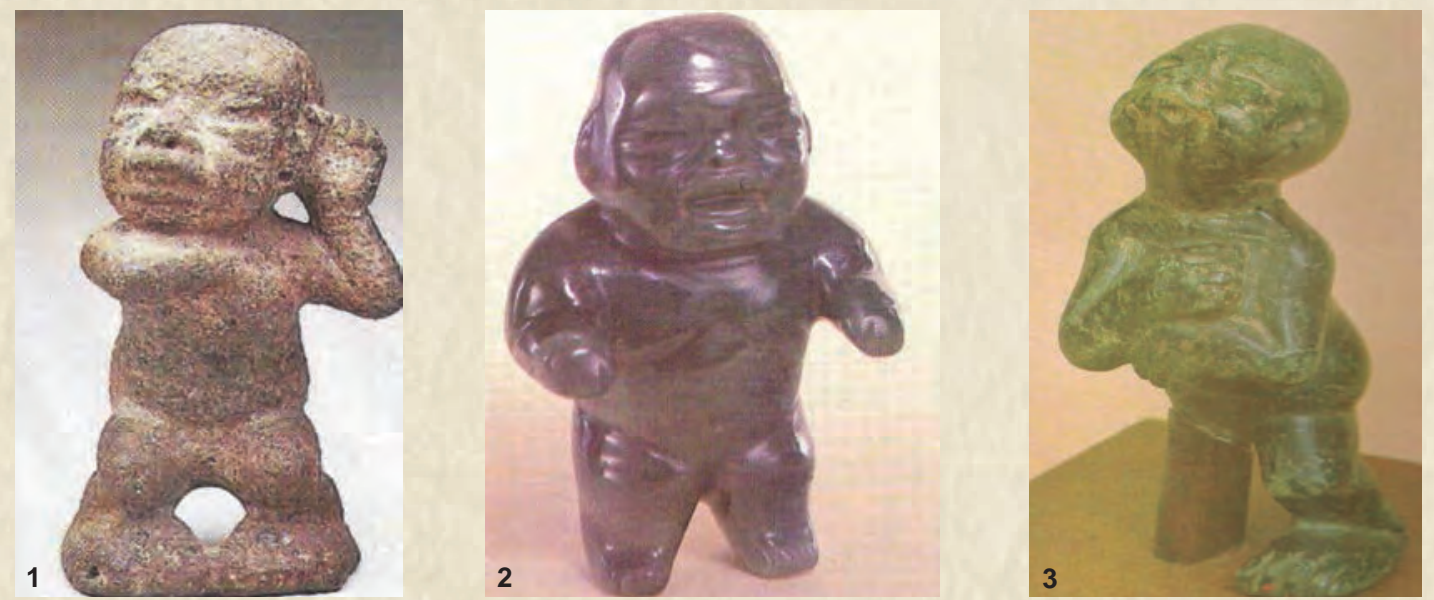

Figuras I, 2 y 3. Figuras masculinas Olmeca en piedra.
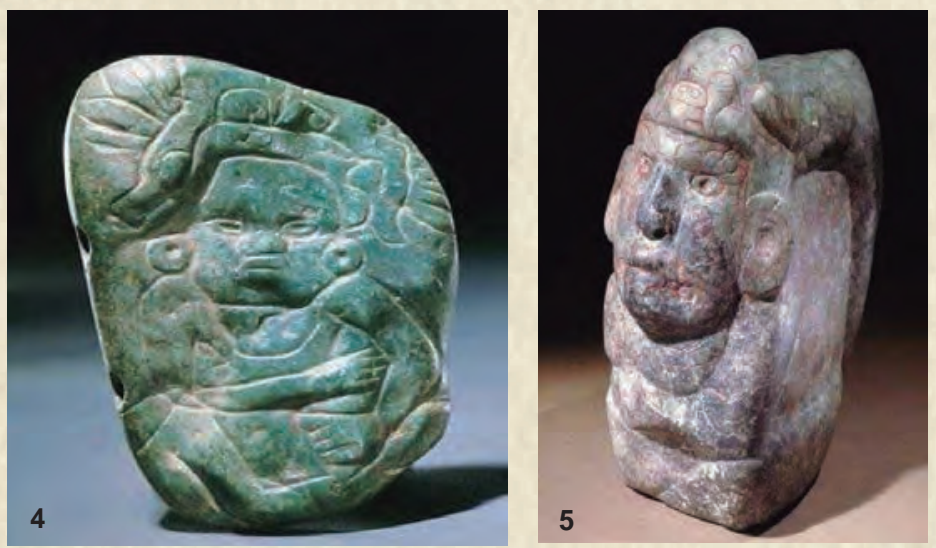

Figuras 4 y $\mathbf{5}$. Figuras masculinas Mayas en piedra.

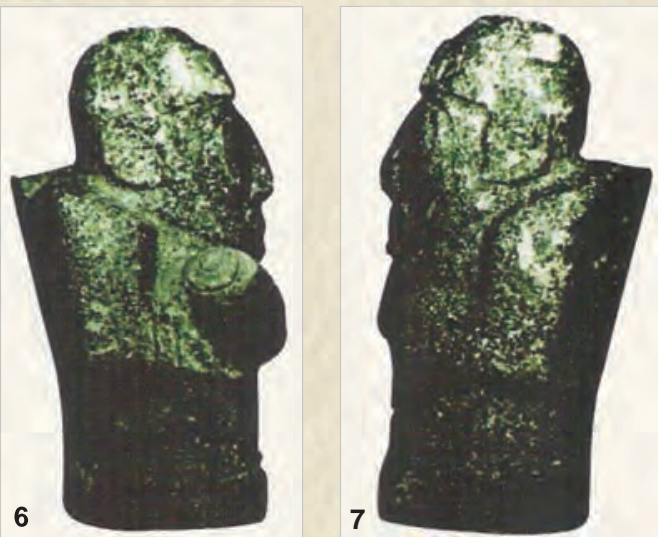

Figuras 6 y 7. Figurinas míticas bolivianas con personajes gibados. 
adornados personajes M ayas de G uatemala elaborados en cerámica (Figuras 9,10,11,12 y 13).

La cerámica Colima muestra a un personaje enano de extremidades cortas y una giba dorsolumbar (Figura 14). En la segunda de ellas, de origen incierto, posiblemente de la cultura colombiana M alagana (Figura 15), de extremidades inferiores cortas, tocando un instrumento de viento curvo que hace recordar a las trompetas de los M oche de Perú. L a cerámica TumacoLa Tolita muestra a un enano de extremidades cortas adornado de pequeñísimas láminas de oro, engastadas en la cerámica, en la frente, orejas, abdomen, genitales, brazos y pies (Figura 16).

La representación de varones enanos en escenas cortesanas del mundo $M$ aya presididas por señores de poder, es un testimonio más del papel que estas personas jugaron en la vida sagrada y profana de casi todas, sino en todas, las sociedades de A mérica precolombina, como se sabe hoy por las mitologías y etnohistorias indígenas. Pero estas representaciones no son sólo un testimonio más, sino que es único en el concierto de todas las de A mérica antigua y además, por cierto, muy parecidas a las que se encuentran en el arte occidental y que dejan ver a personajes muy cortos de talla como ayudantes y practicantes de varios servicios en las cortes europeas.

Son seis escenas las aquí representadas. La primera es un pequeño personaje acostado boca abajo sobre un ideograma de la escritura M aya. (Figura 17). La segunda muestra sobre una tarima a un personaje muy pequeño parado frente a un gran señor sentado y aten-
8

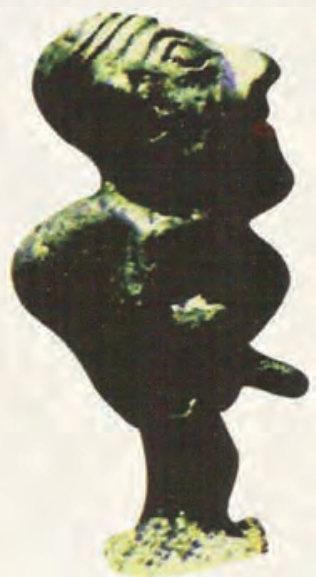

Figura 8. Figurina lítica boliviana con un enano gibado y gran pene erecto.
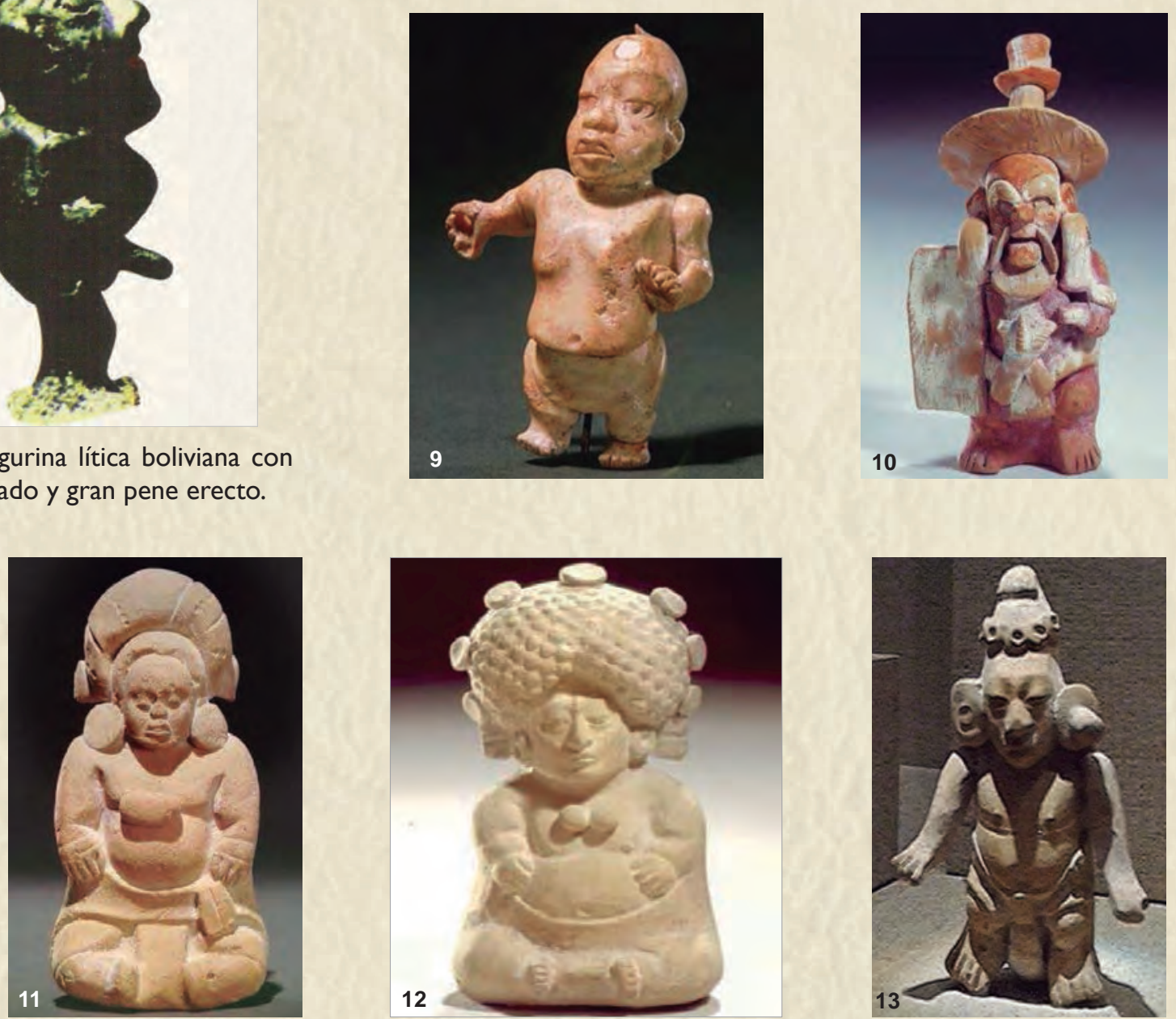

Figuras 9 a 13. Personajes Mayas con enanismo y acortamiento de extremidades elaboradas en cerámica. 

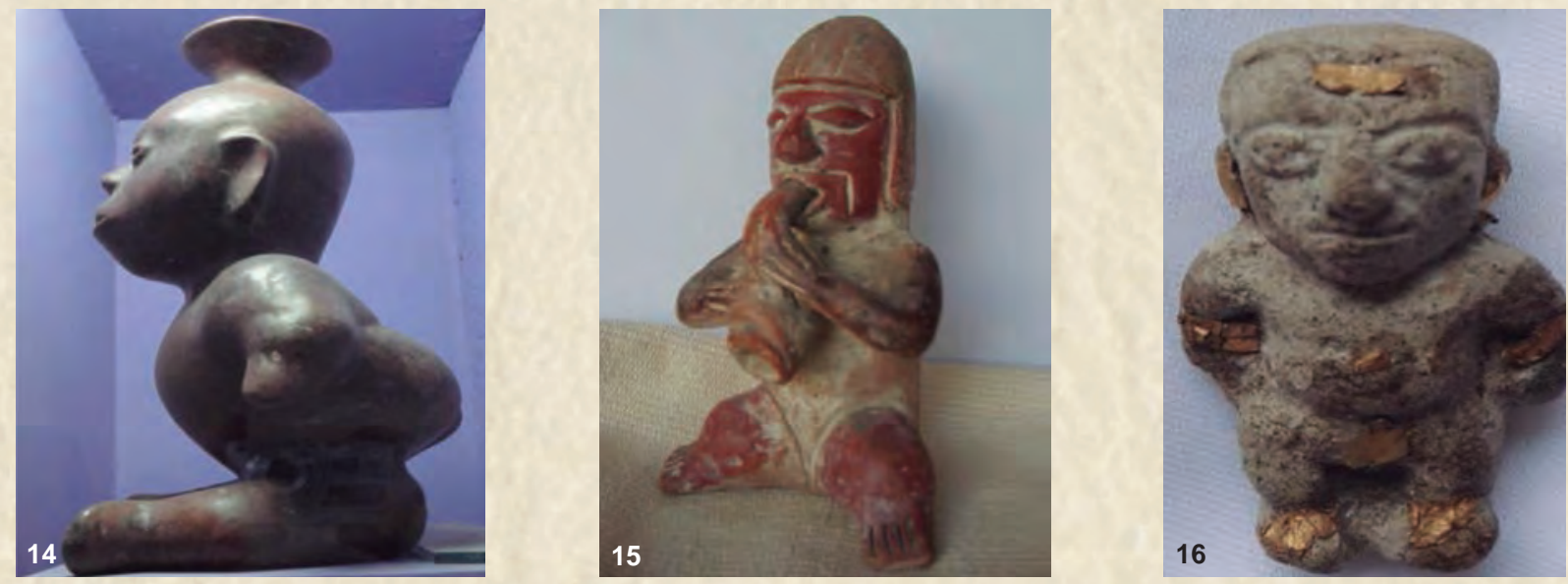

Figuras I4, I5 y I6. Cerámica Colima, posible Malagana y Tumaco-La Tolita, con enanos de extremidades cortas.

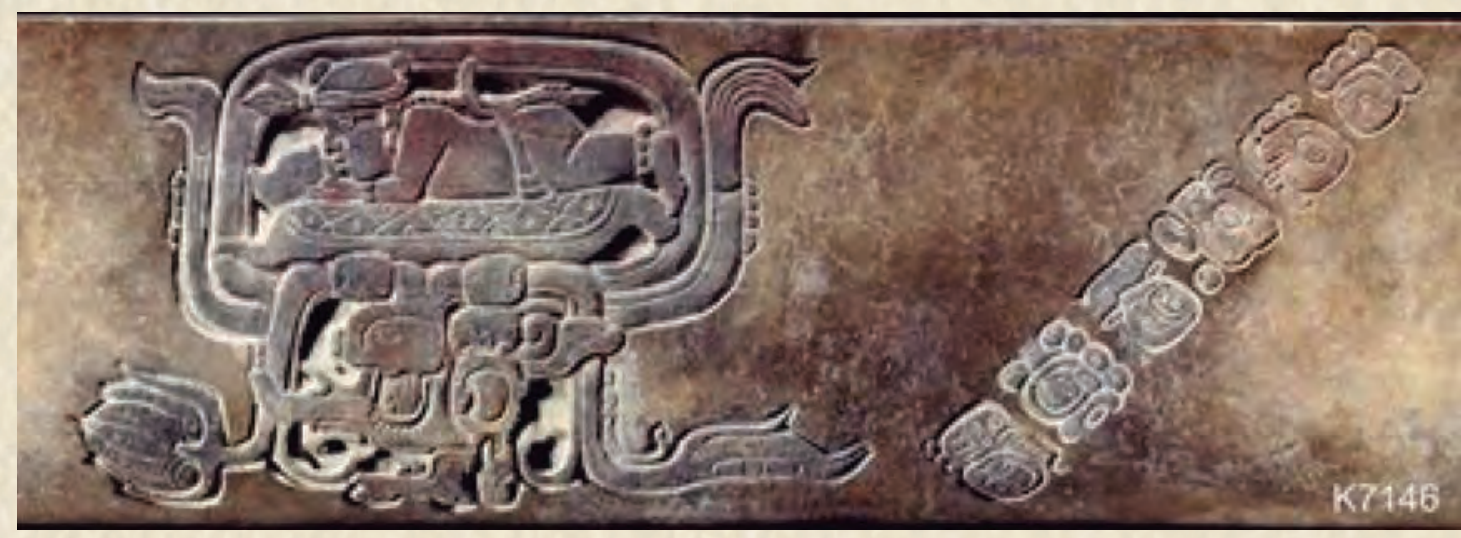

Figura I7. Personaje acostado boca abajo sobre un ideograma de la escritura Maya.

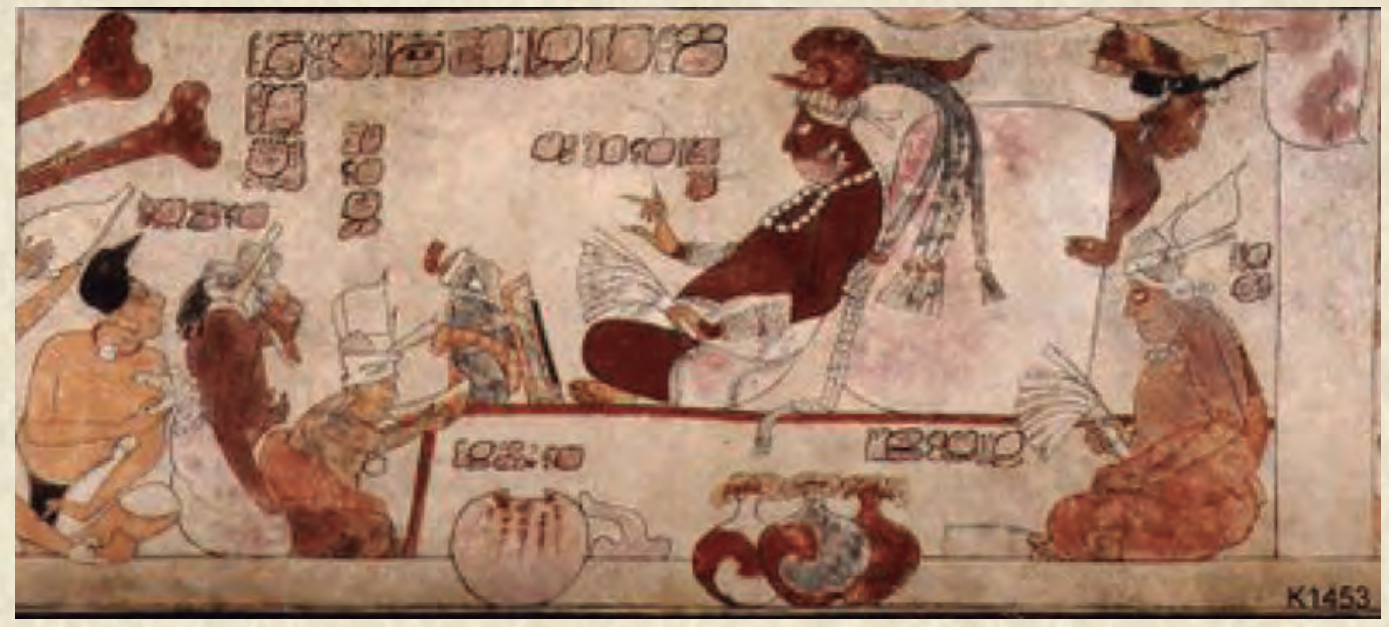

Figura I8. Enano mostrando una tabla a un atento señor con sirvientes.

dido por sirvientes ubicados atrás, mirando atento a una tabla que le presenta la diminuta persona. A la espalda del pequeño enano, pintados como si estuvieran en el piso del recinto están representados otros dos personajes especiales. El primero de ellos de corta talla, aunque más grande que el diminuto, y el segundo de piel más oscura, al parecer jorobado. Por el orden de proximidad al gran señor pareciera que los enanos más pequeños tenían alguna prioridad sobre los menos pequeños y sobre los jorobados. L a representación del 
enano diminuto asociándole con una tabla que parece que leyera el gran señor, remite inmediatamente a la anterior escena descrita, la del enano acostado sobre un ideograma de la escritura M aya (Figura 18).

En la tercera escena se puede ver a un enano de extremidades cortas, con actitud obsecuente, a la izquierda del gran señor que dirige su atención a un viejo (Figr ra 19). En la cuarta escena un enano está en el centro de dos grupos de guerreros con escudos, mientras que la quinta el enano aparece entre dos personajes asociados con las Ilamadas palmas rituales por los investigadores del mundo $\mathrm{M}$ aya (Figuras20y 21). En la sexta escena un enano, en el centro de ella, parece increpar a un prisionero desnudo a quien sujeta por detrás un guerrero, mientras a, la derecha de la escena, un jorobado observa como un guerrero pisotea a otro prisionero desnudo (Figura 22).

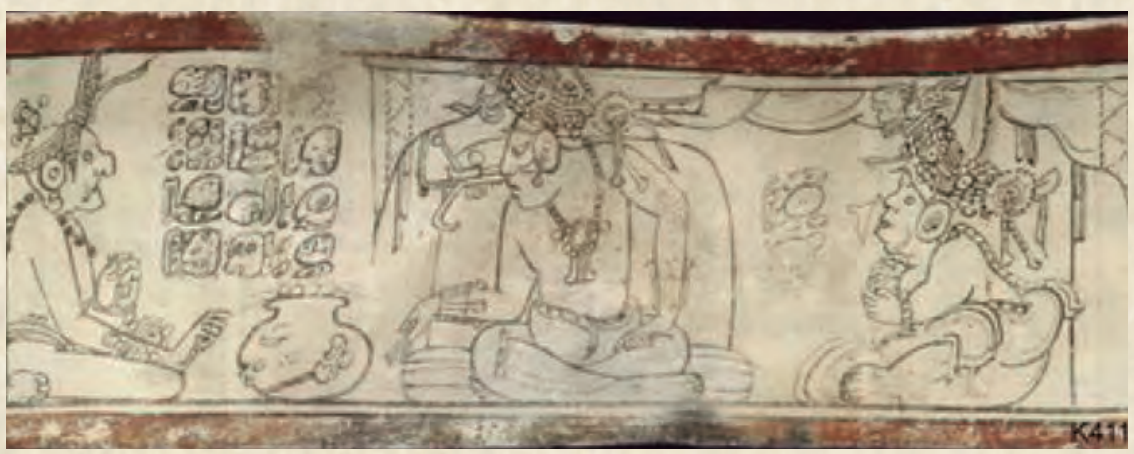

Figura 19. Enano mirando al gran señor y a un viejo.

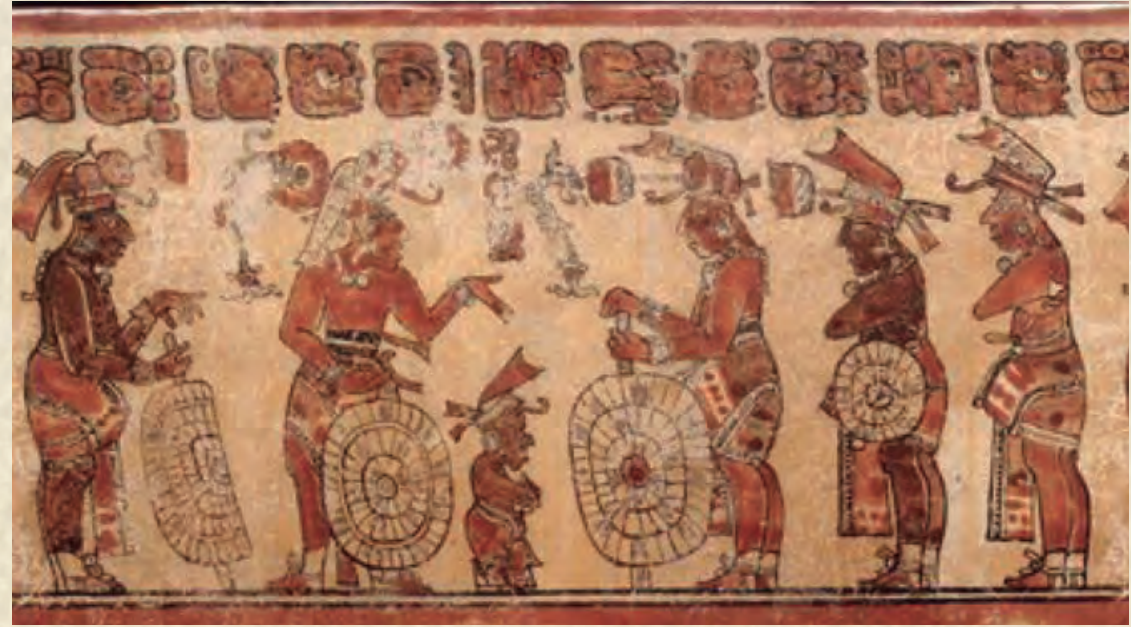

Figura 20. Enano con guerreros.

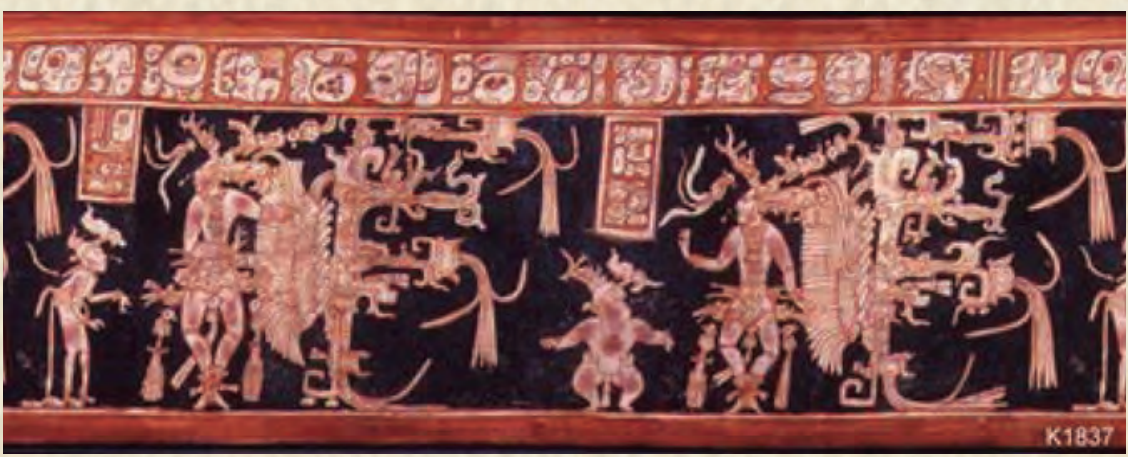

Figura 2 I. Enano con palmas rituales Mayas. 


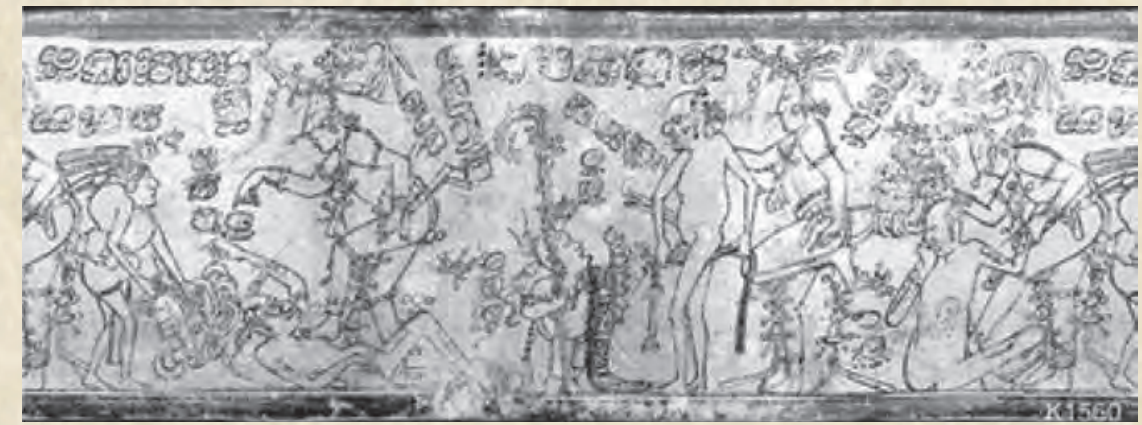

Figura 22. Enano que increpa a un prisionero desnudo, a la derecha un guerrero pisotea a otro prisionero desnudo.

\section{Tipos específicos de enanismo prehispánico}

En nueve figurinas de personajes masculinos, gracias a factores como los pocos adornos y vestidos que llevan y al realismo de su elaboración, se puede intentar hacer un diagnóstico más específico del tipo de enanismo que se representa. Siete de las figurinas son colombianas: seis de la cultura Tumaco-La Tolita y una M alagana; una es mexicana, Azteca y la última es peruana, Chimú.

Una de las figuras Tumaco-L a Tolita, un silbato, representa en el tronco y la cabeza a un personaje con macrocefalia, frente abombada, nariz corta en silla de montar y brazos cortos, con tocado tipo corona de cinco puntas. Con claridad es la representación del tipo más frecuente de enanismo: la acondroplasia. A I coronar a este personaje se revela la importancia que tuvo la talla corta con gran volumen de la cabeza (Figura 23). U na segunda figurina T umaco-L a Tolita muestra a un personaje de talla baja, miembros cortos y rostro brusco 0 abotagado, pero sin la macrocefalia como el anterior personaje analizado. Por estas características puede ser un caso de mucopolisacaridosis o de mucolipidosis (Figura 24).

La tercera figurina Tumaco-La Tolita muestra un personaje con tronco y extremidades cortas pero sin macrocefalia. Puede estar representando una hipoacondroplasia o una pseudoacondroplasia (Figura 25). Por las características de acortamiento a expensas principalmente de los antebrazos y manos la cuarta cerámica Tumaco-L a Tolita puede estar representando un caso de acromesomelia (Figura 26).

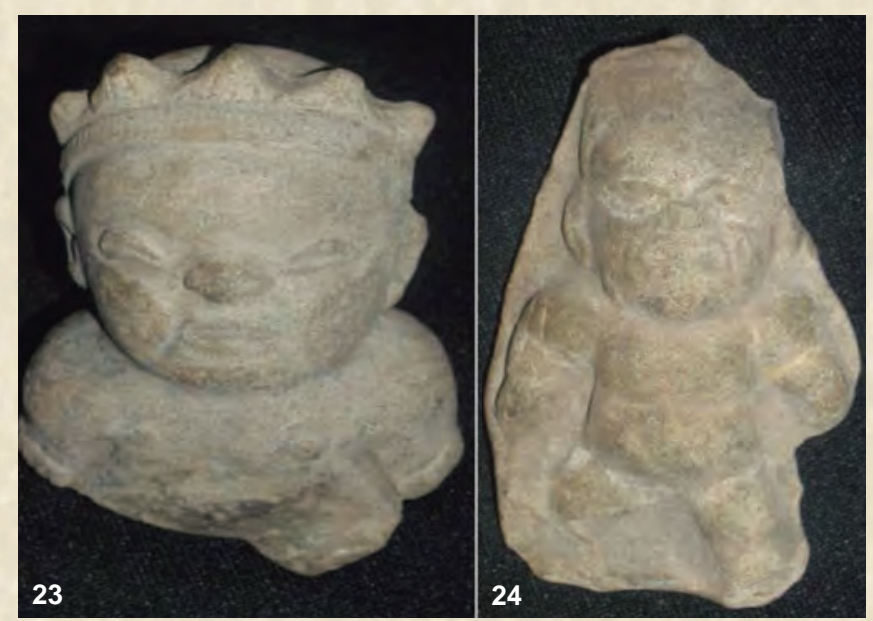

Figuras 23 y 24. La primera representa un enano acondroplásico coronado que revela su importancia. La segunda es similar con talla baja y miembros cortos pero sin macrocefalia, puede corresponder a mucopolisaridosis o mucolipidosis.
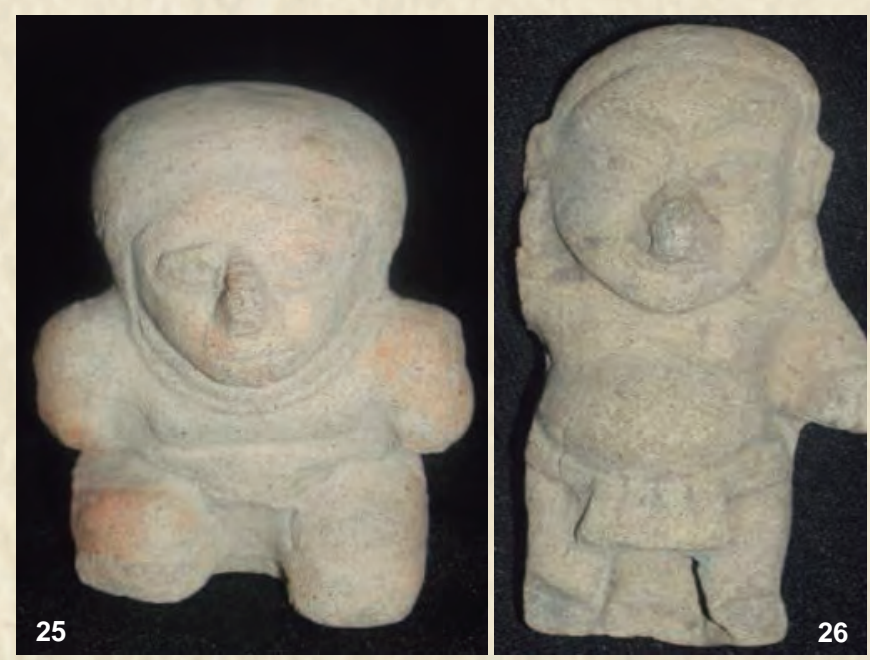

Figuras 25 y 26. La primera puede representar una hipoacondroplasia. La segunda con acortamiento de antebrazo y manos puede ser una acromesomelia. 
El acortamiento del cuello con la gran giba que acorta el tronco y los brazos largos hacen de la quinta cerámica Tumaco-L a Tolita un caso de displasia espóndilo epifisiaria tarda o de M orquio (Figura 27). A unque con menos realismo la escultura lítica de la M alagana muestra también a un personaje que tiene todas las extremidades cortas. ¿U na displasia espóndilo epifisiaria, un síndrome de M orquio? (Figura 28).

La sexta cerámica T umaco-L a Tolita parece corresponder a un caso de una forma dominante de la displasia espóndilo torácica de J eune por la baja talla y el tórax abombado (Figura 29). En la cerámica de la cultura A zteca se ve a un personaje de extremidades cortas y gran cabeza, características de la acondroplasia, haciendo sonar un gran caracol (Figura 30). En la cerámica de la cultura peruana de Chimú se aprecia a un personaje de extremidades cortas y gran cabeza, características de la acondroplasia, tocando un tambor (Figura 31).

\section{Disc usión y conclusiones}

El estudio de los diferentes tipos de enanismo en el arte de las culturas prehispánicas deja ver con claridad que esta característica corporal que hoy se sabe que afecta por igual a ambos sexos, en las sociedades indígenas según la descripciones de Cortés, Díaz del Castillo y Poma de Ayala, solo fue representada en los varones en las sociedades precolombinas, tal vez como expresión de la valoración superior que les dieron a ellos y no a ellas. La figurina Tumaco-L a Tolita (Figura 16) muestra con claridad la asociación entre el enanismo y el oro, vinculado al poder generador sagrado y masculino del sol y su color representativo, el amarillo. El oro y los enanos generan vida, aseguran el ciclo solar.

L a asociación de giba y enanismo que se ve en las tres piezas de Tiwanaku (Figuras 6,7 y 8), en la Colima (Figura 14), en la Tumaco-L a Tolita (Figura 27) y en la M alagana (Figura 28). La relación entre enanos y jorobados observadas en las escenas de las pinturas mayas (Figuras $\mathbf{1 8}$ y 22), además de señalar que en las primeras figurinas el enanismo se manifiesta con al teración de la columna, revela que ambas características se relacionaron en forma simbólica con ciertos factores de alto valor social.

Una de ellas fue la fuerza generatriz como se puede ver en la figurina Tiwanaku (Figura 8) que representa al enano gibado con un gran pene erecto, con el propósito claro de vincular a través de una asociación típica del pensamiento analógico, a la giba con la acumulación
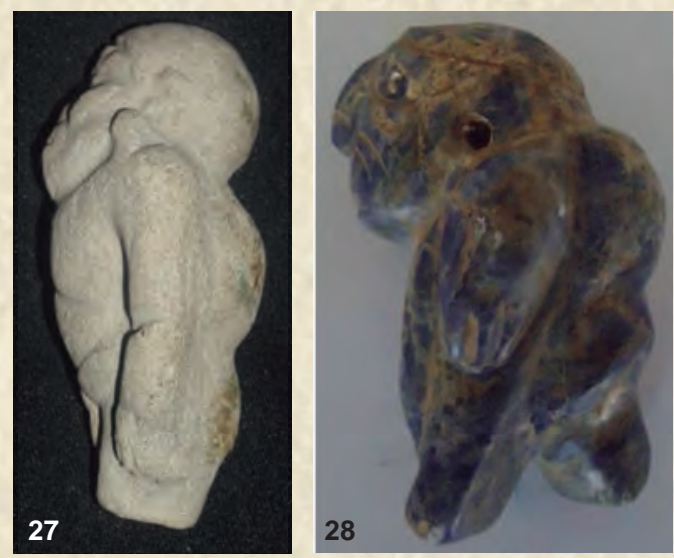

Figuras 27 y 28. La primera con giba, cuello corto y brazos largos puede ser una displasia espóndilo epifisaria. La segunda tiene todas las extremidades cortas.

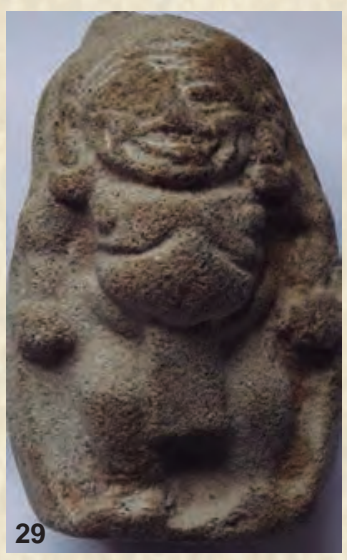

Figura 29. Baja talla y tórax abombado.

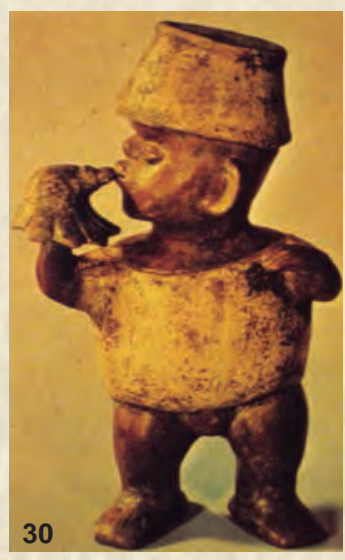

Figura 30. Cerámica azteca de una acondroplasia, haciendo sonar un caracol.

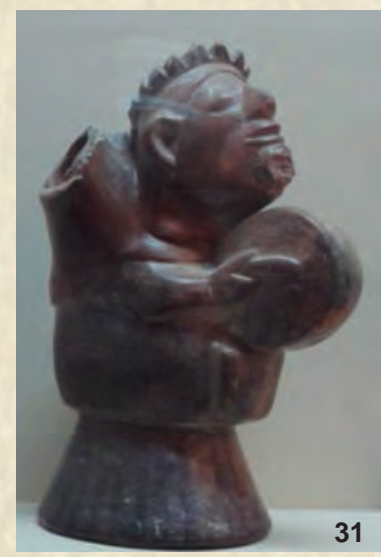

Figura 31. Acondroplasia de la cultura peruana Chimú. 
de poderes y al erecto pene con el poder generador de su dueño: el enano. Este personaje, tan caro a las tradiciones cultural es supérstites del pueblo boliviano, Ekako o Ekeko, es la expresión pura de la fertilidad y la acumulación de bienes.

L os registros antropológicos de diferentes partes del mundo y de A mérica en particular, señalan múltiples ejemplos de la práctica de la masturbación masculina sobre los cultivos recién sembrados. Los enanos en muchas tradiciones del mundo están asociados con los lugares de fuentes de vida: raudales, cascadas, ojos de agua, selvas y bosques.

Otra característica de alto valor social atribuida a los enanos y los jorobados es la acumulación de bienes y conocimientos, como se sabe por la ya mencionada tradición del Ekeko boliviano asociada con las figurinas Tiwanaku (Figuras 6 y 7 ) y por la clara relación con la escritura maya expresada con gran belleza en las escenas de sus pinturas (Figuras 17y 18) . La relación con el conocimiento de enanos y jorobados en los grupos de poder del mundo prehispánico, se ve nítida en las escenas del mundo maya (Figura 22).

La asociación de los enanos varones con la música se representa de una manera diáfana en cuatro cerámicas: la A zteca (Figura 30) en la que un acondroplásico toca un caracol gigante, la Chimú (Figura 31) en la que un acondroplásico toca un tambor, la M alagana (Figura 15) en donde un enano toca una trompeta curva y una figurina Tumaco-La Tolita (Figura 23) en la que un acondroplásico tiene en su espalda tres orificios pequeños que lo convierten en un silbato. Estas cuatro cerámicas señalan la estrecha relación de los enanos, en especial los acondroplásicos los que tenían la cabeza grande, con los momentos solemnes, sagrados, que implicaban la actividad musical en las sociedades prehispánicas.

Todas las anteriores asociaciones con la condición de enanismo, señalan la importancia que el pensamiento analógico tuvo en las sociedades indígenas prehispánicas y en general en todas las sociedades de la antigüedad, como se puede colegir al analizar esta temática. Considérese, a modo de ejemplo, el papel que tuvo el enano acondroplásico en el antiguo
Egipto como protector de las relaciones amorosas, el matrimonio y el nacimiento (Figura 32), el rol que tuvo en la corte faraónica de la V I dinastía del Imperio A ntiguo el enano Seneb, que aquí aparece con su esposa Senetites y sus dos hijos, como encargado del guardarropa del faraón (Figura 33). La vinculación del enanismo con el poder generador como se ve en el enano danzante poseedor de un gran pene, del Gabinete Secreto del M useo de N ápoles (Figura 34), el acondroplásico con su gran pene y con trompeta perteneciente al mundo griego de los siglos IV - II AC (Figura 35) y otro enano acondroplásico con gran pene, lanza y al lado de una grulla del arte griego de los siglos IV -III A C (Figura 36). EI dios hindú $V$ isnú, convertido en forma pasajera en un enano sugestivo de acondroplasia (Figura 37).

El arte grecorromano representó a hombres y mujeres afectados de enanismo, en este caso en cerámicas griegas con figuras rojas de varones desnudos, los dos primeros pintados en un ánfora y un aríbalo, acondroplásicos (Figuras 38 y 39) y al tercero vestido, picnodisostósico (Figura 40) en proximidad con los animales, perros y liebres, a manera de mascotas.

Diferentes consideraciones pueden y deben hacerse con las representaciones de enanos y enanas: el arte pictórico europeo a partir del siglo X V a diferencia del arte prehispánico representa a enanas. L os enanos varones de las cortes de la E uropa cristiana al no exhibir

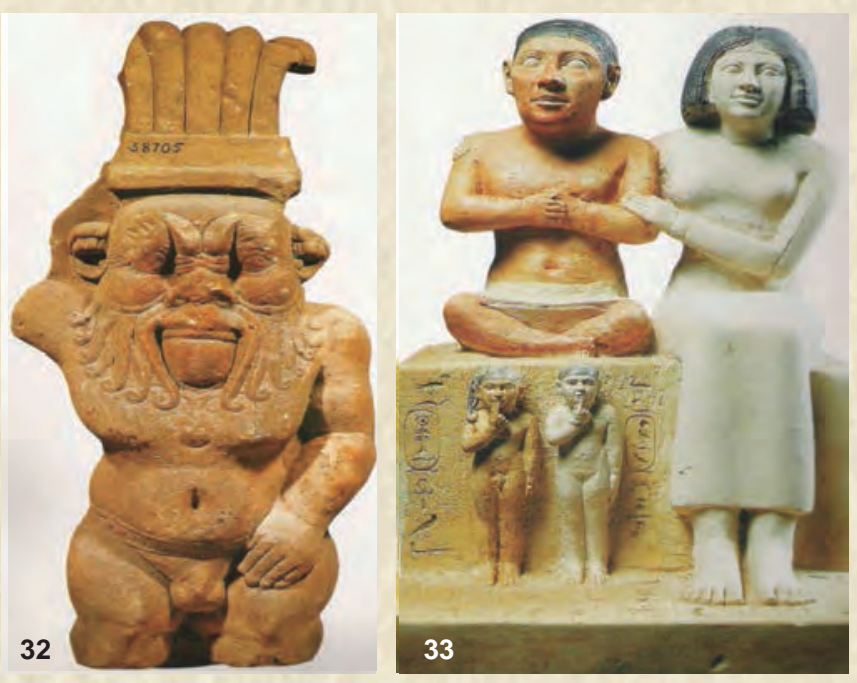

Figuras 32 y 33. Papel importante que tuvo el enano acondroplásico como protector del amor en el antiguo Egipto. 

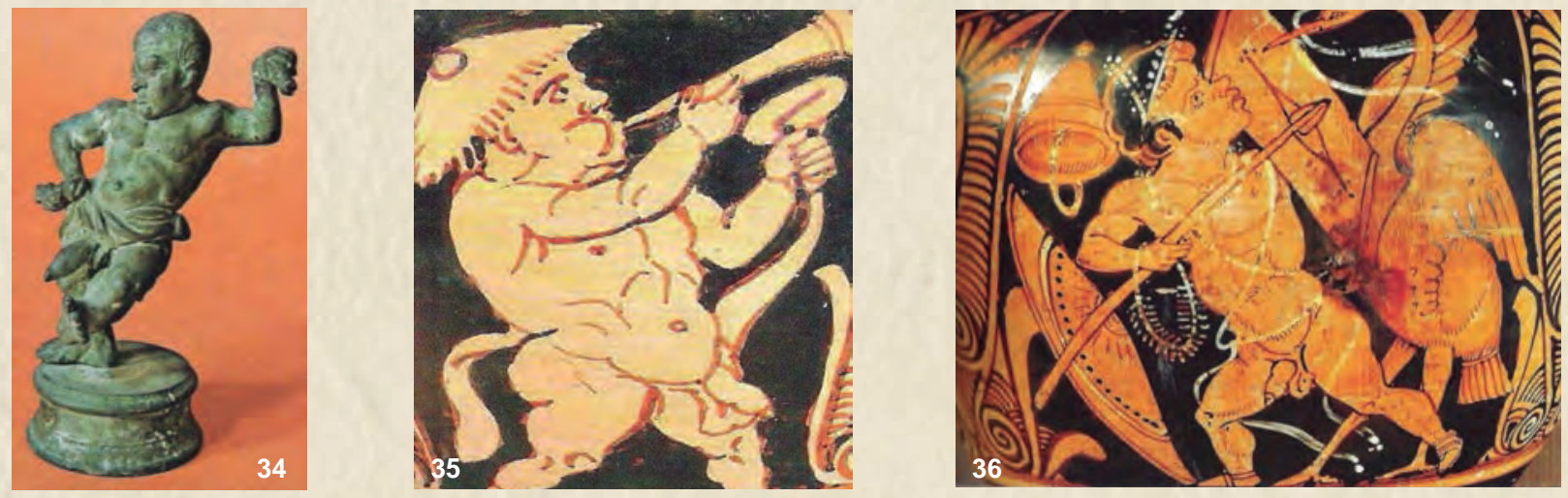

Figuras 34, 35 y 36. Enanos acondroplásicos con gran pene.

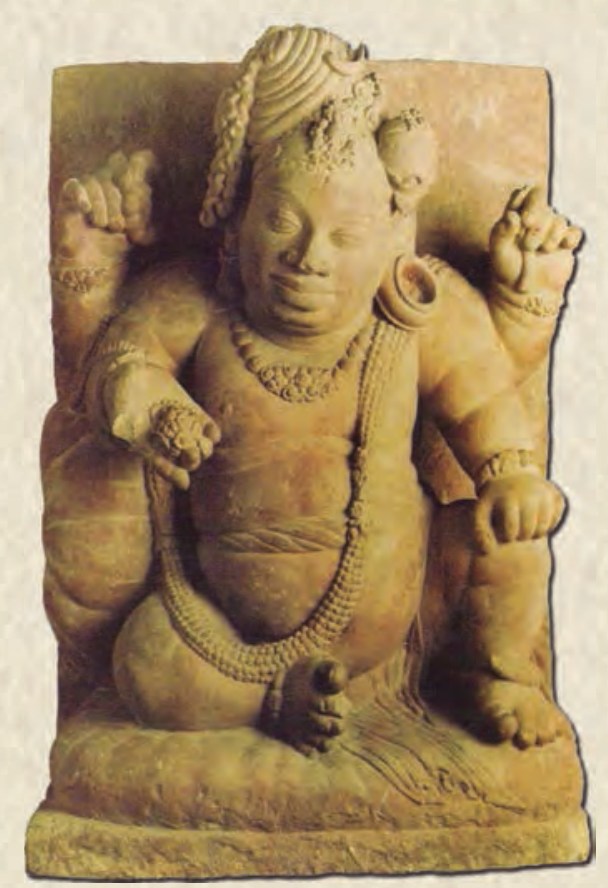

Figura 37. Dios Visnú convertido en forma pasajera en enano de aspecto acondroplásico.

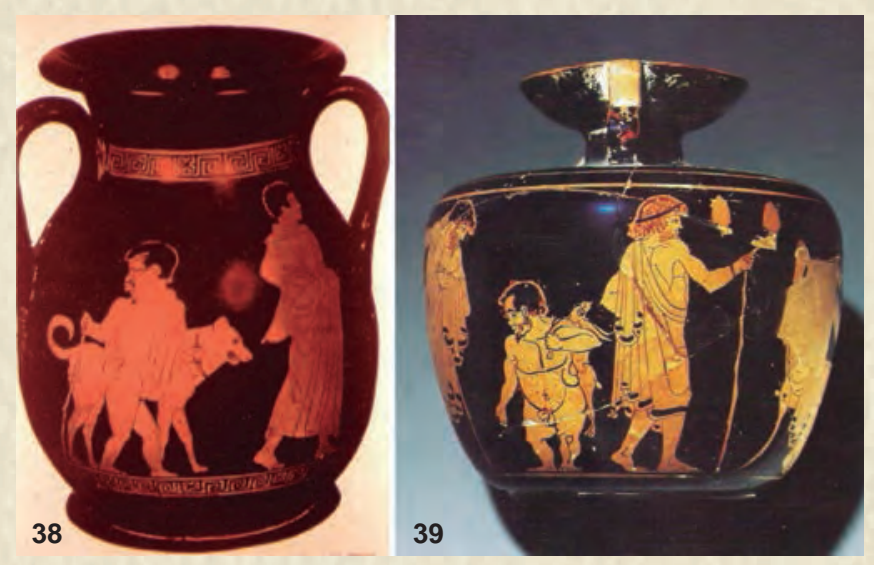

Figuras 38 y 39. Dos ánforas griegas con enanos acondroplásicos.

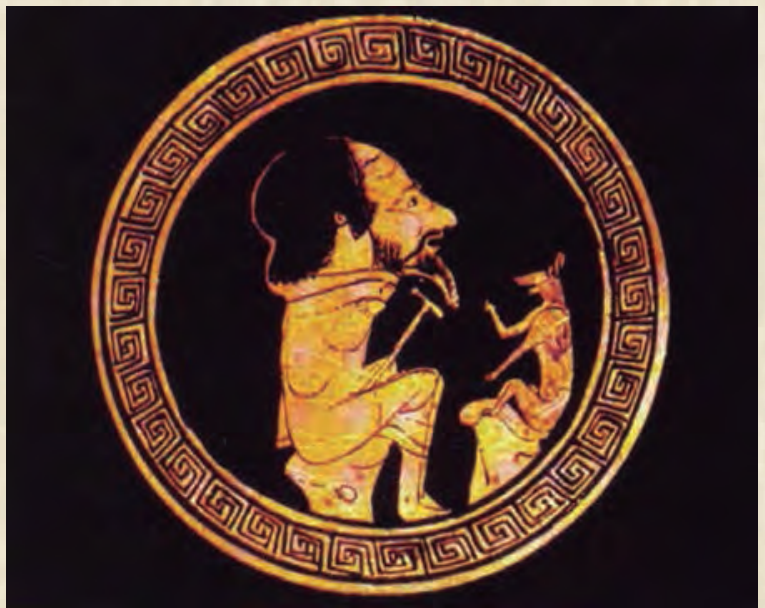

Figura 40. Enano picnodisostósico con mascotas animales.

su pene, ya no podían mostrarse por sí mismos como fuente de poder fertilizante y abundancia de bienes. Ellos y ellas fueron exhibidos por los reyes y príncipes como fuente de su capacidad de acumular seres extraños y para atraer la atención de sus pares y súbditos. En muchos de los cuadros de famosos pintores europeos aparecen enanos y enanas acompañados por mascotas, como queriendo asimilar a dichos seres humanos con esta triste condición (Figuras 41 a 52 ).

El realismo de estas pinturas ha permitido a la ciencia médica de hoy en día los siguientes diagnósticos: acondroplasia (Figuras 41, 45,46, 49y 51); displasia espondiloepifisiaria o pseudoacondroplasia (Figura 42), displasia espondiloepifisiaria (Figuras 43, 44 y 50), con déficit hormonal (también Figura 44), hipotiroidismo (también Figura 49), déficit hipofisiario (Figuras 47 y 52) y pseudoacondroplasia (Figura 48). 
L a española fue la corte europea que más enanos poseyó. J osé M oreno V illa, en su libro L ocos, enanos, negros y niños palaciegos que tuvieron los Austrias en la Corte española desde 1563 a 1700 contabilizó y describió la vida de veintinueve enanas y cuarenta enanos.
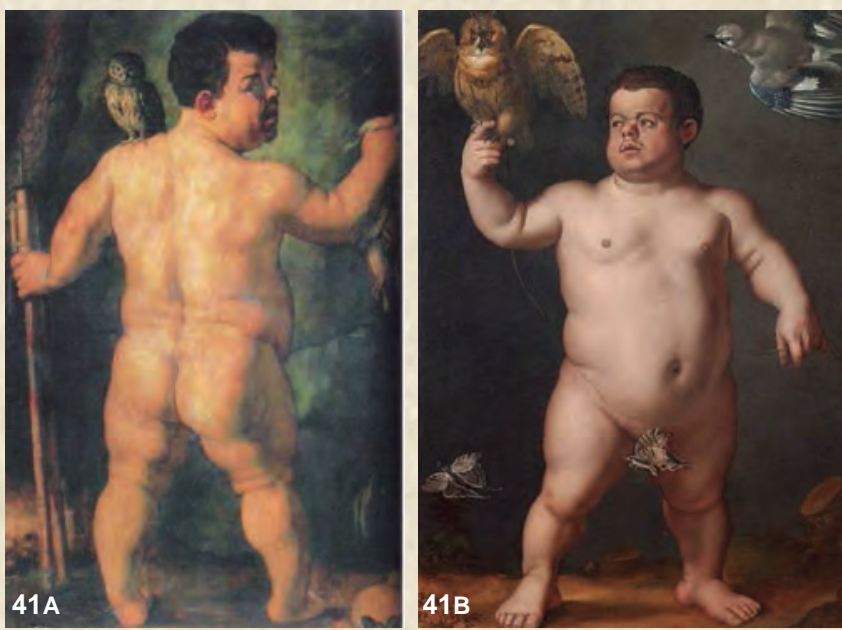

Figura 4 I A y B. El enano Morgante de espaldas y de frente con un buho en el hombro izquierdo y en la mano derecha. Agnolo Bronzino, siglo XV.

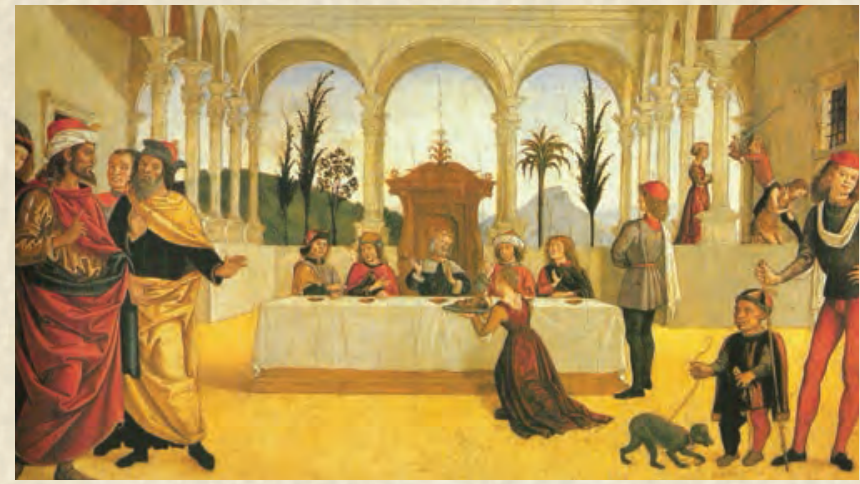

Figura 42. Enano que lleva un perro. Salomé lleva a Herodes la cabeza de Juan Bautista. Atribuido a Antoniazzo Romano, hacia 1490.

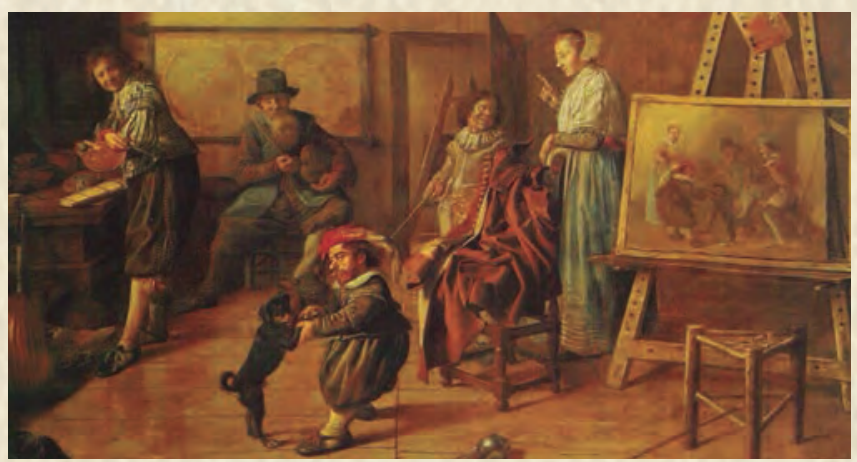

Figura 43. Enano jugando con un perro. El taller del Pintor. Jan Miense Molenaer, hacia 1610.

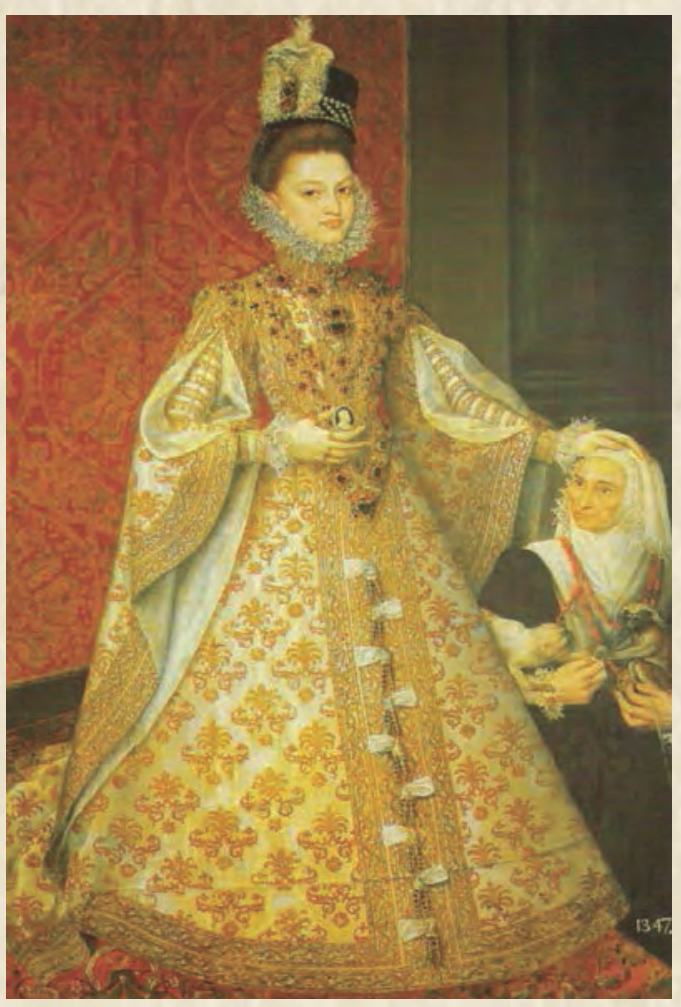

Figura 44. La infanta Isabel Clara Eugenia de España con la enana Magdalena Ruiz, que sostiene en su mano izquierda un mico y en su derecha un perro.Teodoro Felipe de Riaño, hacia I5I5.

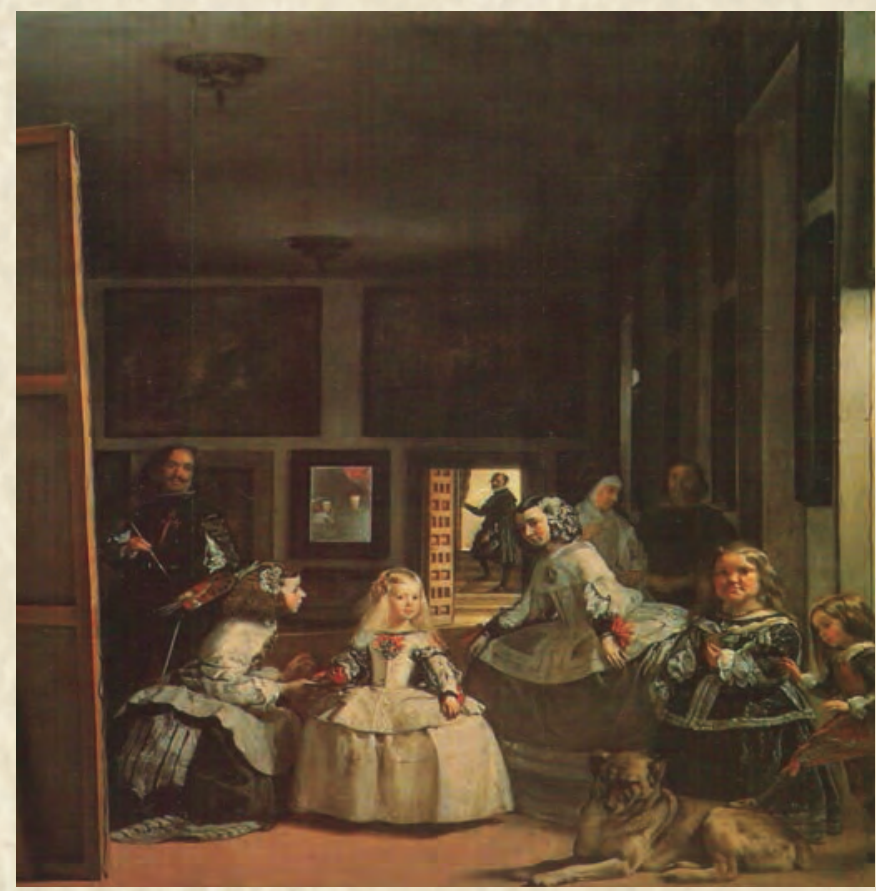

Figura 45. Las Meninas. La enana María Barbola (iacondroplasia?) y a su pies un mastín. Diego de Silva Velázquez, 1656. 


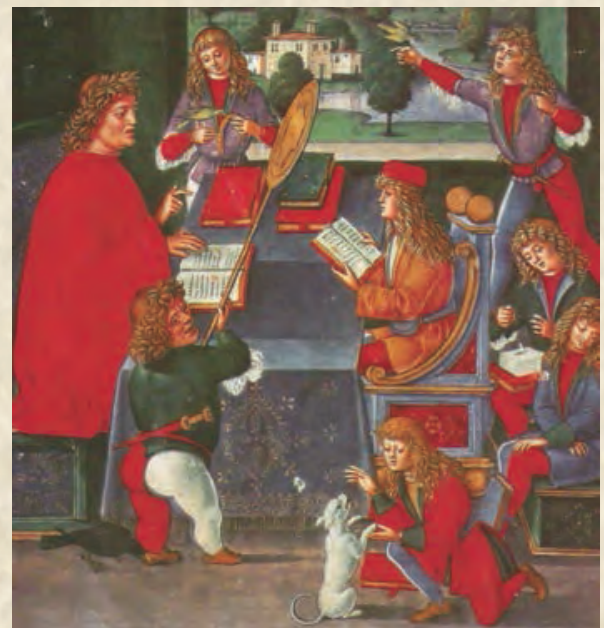

Figura 46. Miniaturas acerca de: Aelius Donatus, Ars Minor; Disticha Catonis; Institutiones grammaticae. Giovanni Pietro Birago (entre I47I y I5I3).

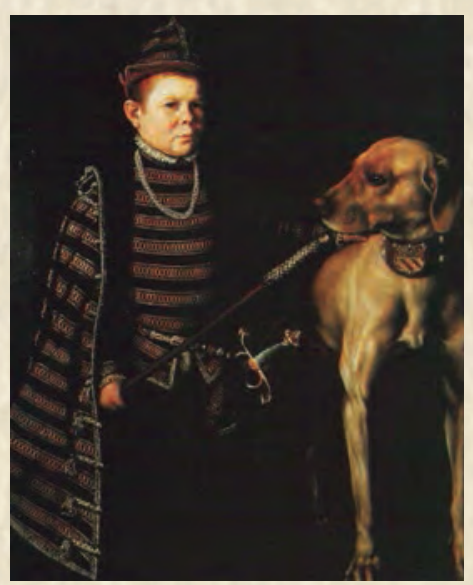

Figura 47. Estanislao, el enano del cardenal Granvella.Anthonis Mor, siglo XVI.

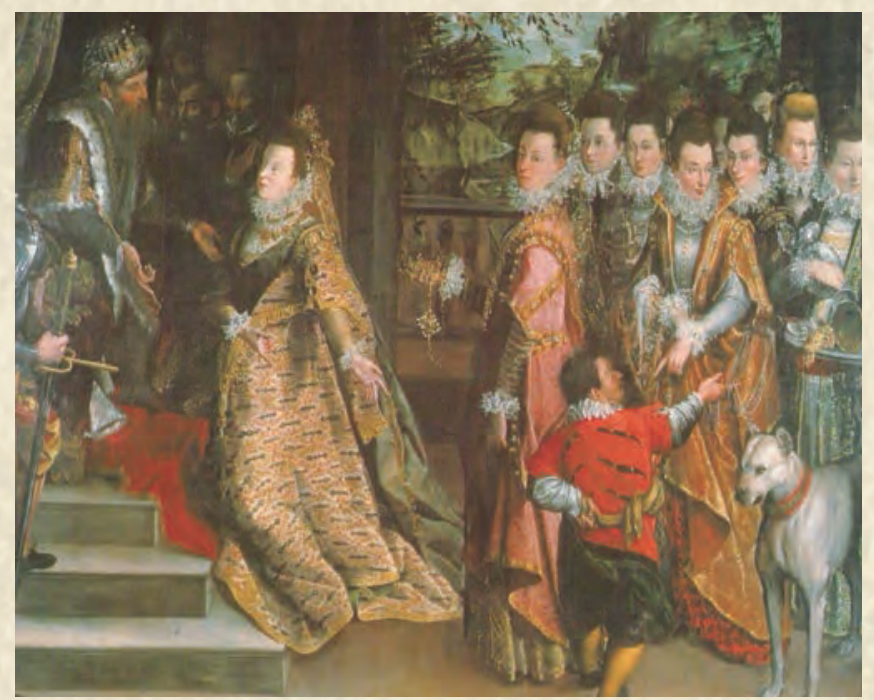

Figura 48. La reina de Saba en la corte del rey Salomón. Lavinia Fontana (1552-1614).

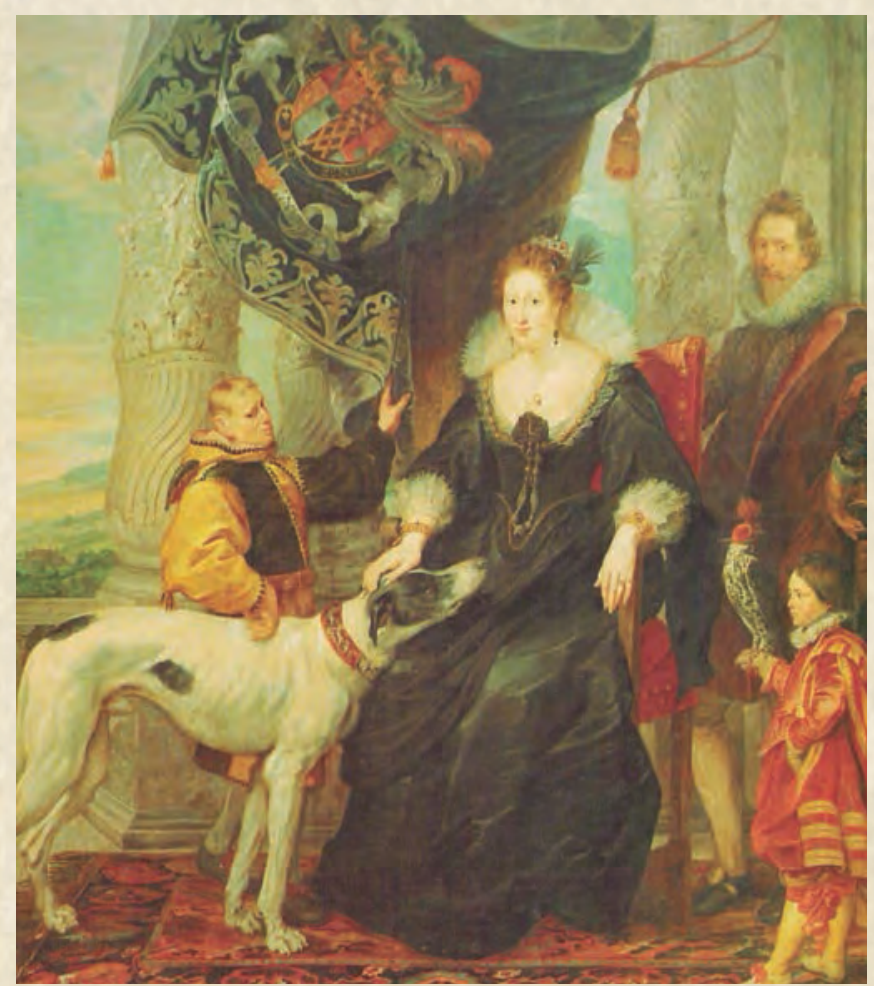

Figura 49. El archiduque Fernando con un enano en la corte. Joseph Heintz el viejo, 1609.

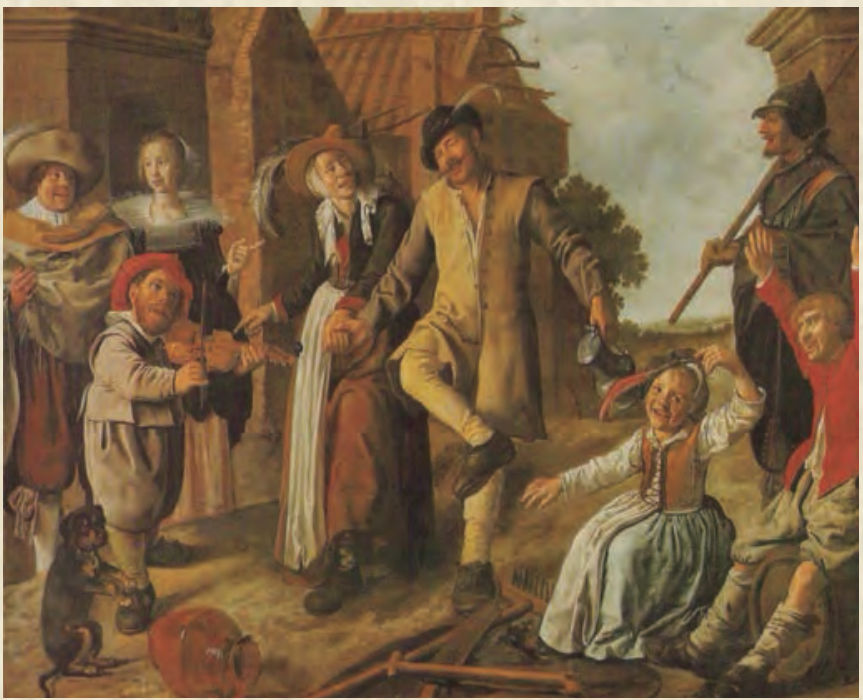

Figura 50. Pareja danzante en la calle del pueblo. Jan Miense Molenaer, hacia 1610. 


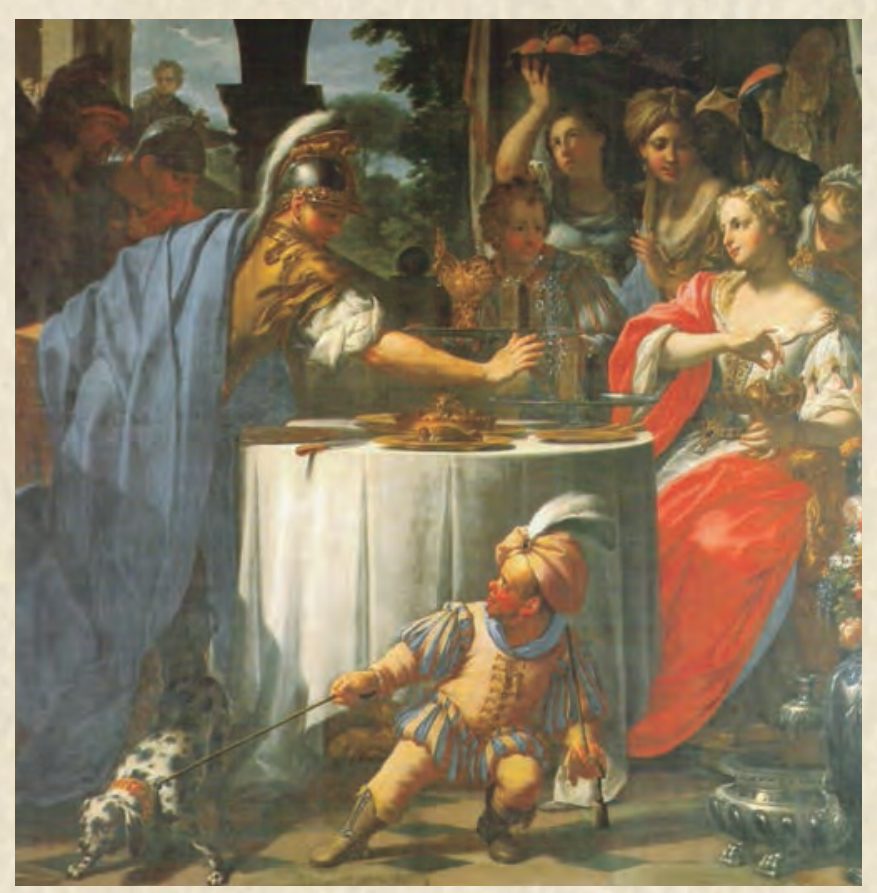

Figura 5 I. El banquete de Cleopatra. Francesco Trevisano, llamado Romano. (1656-I746).

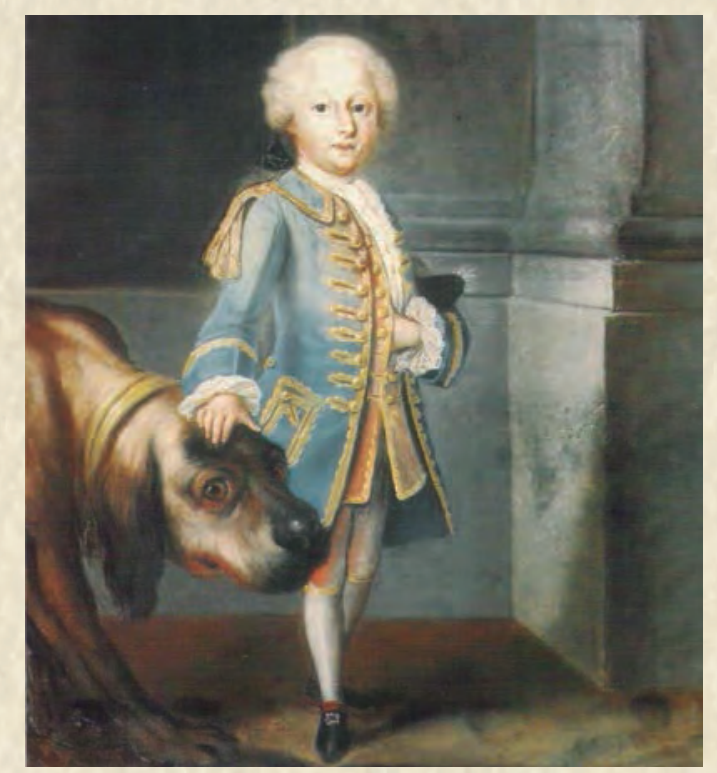

Figura 52. Nicholas Ferry, llamado Bebé, con perro.Anónimo, mediados del siglo XVIII.

Esta búsqueda de personas con enanismo para las cortes europeas puede verse como una forma de coleccionismo o una metáfora que hace alusión a la acumulación de riquezas y capital por parte de los reyes y príncipes europeos. Es una evidencia de la consideración de las personas "diferentes" como bienes u objetos.
Como ejemplo de lo anterior y del deseo de adular y congraciarse con los reyes se relata que un virrey de la Nueva Granada hoy Colombia regaló a los Borbones de España un enano y un gigante que "consiguió" en dos lugares diferentes de su jurisdicción. José M anuel Groot narra en su Historia Eclesiástica y civil de la Nueva Granada (capitulo XXXIV del tomo II) y bajo el epígrafe capitular de "EI pigmeo M achado y su criado son enviados al Rey" narra cómo el virrey de la N ueva Granada, el arzobispo A ntonio Caballero y Góngora, remitió a la Corte española un enano y un gigante en un llamativo episodio ocurrido en julio de 1786: Caballero y Góngora, hombre a quien llamaban la atención todos los fenómenos de la naturaleza, estando aún en C artagena remitió al Rey, con el Capitán de la Corona don Miguel Raon, un enano natural de la ciudad de Cartago, llamado Antonio Machado, como objeto digno de la curiosidad de un príncipe, por las raras cualidades que reunía. Tenía 22 años de edad y su estatura era como la un niño de cinco. Sabía leer y escribir; tocar violín y guitarra; bailaba y montaba a caballo con suma habilidad y destreza; de genio despejado y vivo, su conversación era agradable y chistosa. Pero lo más particular era la buena proporción de sus miembros, pues no tenía la deformidad de los enanos, sino que era un hombre en disminución perfecta.

A I mismo tiempo que llegó el enano a Cartagena, supo el señor Góngora que en una estancia tenían un esclavo de estatura gigantesca y para que el real presente que iba a hacer a la Corte tuviera la particularidad de la antítesis, lo compró para enviarlo de criado del enano, quien apenas le llegaba a la rodilla, no excediendo en edad, el criado al amo, más que en dos años. El enano era hijo natural y su madre lo cedió gustosa al A rzobispo V irrey, quien le dejó asegurada una pensión vitalicia para su subsistencia.

El M inistro J osé de Gálvez, en carta fechada en M adrid el 6 de diciembre de 1786, avisó recibo al señor C aballero y Góngora del envío del enano, en estos términos: Ha sido de la aprobación del Rey el que V.E., por los justos motivos que expresa en su carta de 10 de julio próximo pasado, número 1202, haya mandado gratificar por las reales cajas de Cartago con doscientos 
pesos a doña Margarita Machado, madre del enano don J osé Antonio Machado, que se ha presentado ya a S.M. y se ha nombrado enano suyo con entrada en su cuarto. Y en cuanto a la pensión vitalicia que haya de concederse a doña Margarita, quiere el Rey que V.E. señale la que parece justa y correspondiente a sus necesidades y dé cuenta para la real aprobación. Dios guarde a V.E. muchos años." 15

L os enanos y enanas de las cortes europeas anticiparon a aquellas otras personas que por sus características físicas bien diferentes y extraordinarias fueron exhibidas, explotadas económicamente en los circos a partir de comienzos del siglo XIX y marginadas de la sociedad a través de estigmas. Con el desarrollo del capital ismo las personas enanas dejaron de verse como unas mensajeras de ciertas ideas, para convertirse en simples sujetos cuyo valor principal era el comercial. Se dejaron de considerar a través del pensamiento analógico para hacerlo por el analítico, el que cuenta y mide, tan propio de la modernidad iniciada en el siglo XV .

Con el desarrollo en el siglo XIX de las tres mentalidades científicas de la medicina, la anatomopatológica, la fisiopatológica y la etiopatológica, y con el surgir de la teratología como disciplina científica vinculada a esas mentalidades, el enanismo comenzó a ser objeto de un análisis riguroso y profundo que hoy se ve reflejado con claridad en el estudio de cada caso que se presenta.

El siglo XX profundizó en el estudio analítico, médico científico, de los diversos tipos de enanismo y generó una gran discusión y avance en la consideración de los derechos humanos de las personas afectadas por esa patología, orientados a su inclusión en la sociedad y superar los estigmas. Hoy las personas con enanismo no se asocian con la fuerza generatriz, la riqueza, la prosperidad, el conocimiento, ni son vinculadas con la música como lo fueron en las sociedades prehispánicas, sino miradas como seres afectados por enfermedades, curiosos y feos, y con dificultades para su realización laboral, amorosa y sexual.

\section{Referencias}

1. Sotomayor Tribín HA, A rwu V iku, M orales M ales $P, A$ ndi A rimuya $N$. Encuentro de saberes entre profesionales universitarios y médicos tradicionales indígenas en la interpretación de unas representaciones de deformaciones craneanas en el arte prehispánico colombo ecuatoriano y de un instrumento posiblemente quirúrgico del norte del Perú. XI congreso de la A sociación L atinoamericana de A ntropología Biológica (ALA B); 2010 Oct. 21-25; Bogotá, Colombia.

2. Cómo doña M arina era cacica e hija de grandes señores de pueblos y vasallos, y de la manera que la dicha doña M arina fue traída a Tabasco. En: Díaz del Castillo B. Historia verdadera de la conquista de la Nueva España. Barcelona: Editorial Planeta; 1992. p. 262

3. Cortés H. Cartas de la Conquista de M éxico: carta segunda. M adrid, España: Biblioteca de la Historia Sarpe; 1985.

4. Guamán Poma de A yala F. Nueva crónica y buen gobierno. Crónicas de A mérica. Historia 16. M éxico: FCE; 1987.

5. Sotomayor Tribín HA . Enfermedades en el arte prehispánico colombiano. Boletin M useo del Oro. 1990; 29: 63-73.

6. Sotomayor Tribín HA. A rqueomedicina de Colombia prehispánica. Bogotá: Universidad M ilitar nueva Granada; 1999.

7. Sotomayor Tribín HA. Arqueología, arte y paleopatología en América precolombina. En: Sotomayor Tribin HA, Cuellar Z. Aproximaciones a la paleopatología en América Latina. Bogotá: Convenio A ndrés B ello, A cademia Nacional de M edicina de Colombia; 2007. p. 35-78

8. Sotomayor Tribín HA. Paleopatología en Colombia prehispánica. En: Sotomayor Tribin HA, Cuellar Z. Aproximaciones a la paleopatología en América Latina. B ogotá: Convenio A ndrés B ello, A cademia Nacional de M edicina de Coombia; 2007. p. 135-77.

9. Sotomayor Tribín HA. Enanos y gigantes en mitologías indígenas y la arqueología de Colombia. Repert Med Cir. 2007; 16(2): 96-104.

10. Enderle A, M eyerhöfer D, Unverfehrt G, editores. La gente diminuta en el gran arte. Hipocrecimiento desde el punto de vista artístico y médico. Berlín: Artcolor; 1994

11. Ornert DJ, Putschar WGJ. Identification of pathological conditions in human skeletal remains. W ashington: Smithsonian Institution Press; 1985.

12. B autista M artínez J, Romano Pacheco A. Los enanos en M esoamérica. Un caso del Occidente de M éxico. Est A ntropol Biol. 2003; 11(2):761-72.

13. Bautista M artínez J, Ortega Palma J, Gómez V al dés JA. Los Patologías sobresalientes en la Colección Solórzano. Est A ntropol Biol. 2005; 12: 839-48.

14. Jones KL. Smith patrones reconocibles de malformaciones humanas. 6 a ed. Madrid: Elsevier / Saunders; 2007

15. Sotomayor Tribín HA. Enanismo en aspectos históricos y geográficos de algunas enfermedades importantes en Colombia. B ogotá: U niversidad M ilitar Nueva Granada, Editores Gráficos Colombia; 2012 